\title{
Thiol/Disulfide Homeostasis in Bipolar and Unipolar Depression
}

\author{
Gamze Erzin ${ }^{1}$, Güven Özkaya ${ }^{2}$, Canan Topçuoğlu ${ }^{3}$, Rabia Nazik Yüksel ${ }^{4}$, Özcan Erel $^{3}$, Emine Feyza Yurt', \\ Erol Göka ${ }^{4}$, Sinan Gülöksüz ${ }^{5,6}$ \\ ${ }^{1}$ Department of Psychiatry, Ankara Dışkapı Yıldırım Beyazıt Training and Research Hospital, Ankara, ${ }^{2}$ Department of Biostatistics, Faculty of \\ Medicine, Bursa Uludağ University, Bursa, ${ }^{3}$ Department of Biochemistry, Bilkent City Hospital, Ankara, ${ }^{4}$ Department of Psychiatry, Bilkent City \\ Hospital, Ankara, Turkey, ${ }^{5}$ Department of Psychiatry and Neuropsychology, School for Mental Health and Neuroscience, Maastricht University \\ Medical Center, Maastricht, The Netherlands, ${ }^{6}$ Department of Psychiatry, Yale University School of Medicine, New Haven, CT, USA
}

\begin{abstract}
Objective: Bipolar disorder and unipolar depressive disorder are complex phenotypes. There appear to be phenotypical, mechanistic, and therapeutic differences between bipolar depression (BD) and unipolar depression (UD). There is a need for understanding the underlying biological variation between these clinical entities. The role of oxidative processes underlying bipolar disorder and depression has been demonstrated. Thiol-disulfide homeostasis (TDH) is a recent oxidative stress marker. In this study, we aimed to inspect patients with bipolar depression and unipolar depression in terms of thiol-disulfide balance and to compare them with healthy controls.

Methods: Patients admitted to the outpatient clinic of Ankara Numune Training and Research Hospital and diagnosed either as a depressive episode with bipolar disorder $(n=37)$ or unipolar depression $(n=24)$ according to DSM-5 criteria, along with healthy controls $(\mathrm{HC})(\mathrm{n}=50)$, were included in the study. Native thiol, total thiol, and disulfide levels were compared across the groups.

Results: In comparison to HC, both BD and UD groups had higher disulfide levels, disulfide/native thiol ratio, and disulfide/total thiol ratio. No significant differences between BD and UD were detected in terms of disulfide level, disulfide/native thiol ratio, and disulfide/total thiol ratio.

Conclusion: Increased levels of disulfide, native thiol, and disulfide/total thiol ratios compared to healthy controls in both UD and BD groups may be indicative of the presence of oxidative damage in these two clinical conditions. To clarify the role of oxidative stress in the pathophysiology of depressive disorders and investigate TDH, longitudinal studies in patients with medication-free UD and BD are required.
\end{abstract}

KEY WORDS: Oxidative stress; Bipolar depression; Unipolar depression; Mood disorder.

\section{INTRODUCTION}

Bipolar disorder and unipolar depression (UD) cause impairments in functioning and health-related quality of life $[1,2]$. Mood disorders have an array of active constituents such as neurotransmission and immune dysfunction, chronobiology and mitochondrial dysfunction [3]. Recent studies on the inflammatory and oxidative processes have accelerated the understanding of the patho-

Received: January 10, 2020 / Revised: February 6, 2020 Accepted: February 7, 2020

Address for correspondence: Gamze Erzin Department of Psychiatry, Ankara Dışkapı Yıldırım Beyazıt Training and Research Hospital, Ziraat Mah. Şehit Ömer Halisdemir Cad. No: 20, Altındağ, Ankara 06110, Turkey E-mail: gamze.erzin@gmail.com ORCID: https://orcid.org/0000-0001-8002-5053 physiology of mental disorders $[4,5]$. There is a fast-growing set of evidence suggesting that oxidative stress is involved in the pathophysiology of UD and bipolar disorder $[6,7]$.

Excessive production of free radicals (reactive oxygen species) play an important role in the promotion of permanent degradation of equilibrium among antioxidants in cell and prooxidant processes, in oxidative stress. Free radicals cause damage to proteins, lipids and deoxyribonucleic acid (DNA) in the cell, triggering apoptosis and cell death [8]. Mental disorders, including UD, bipolar disorder, and schizophrenia are affected by oxidative stress through this mechanism [9-11].

There are different methods for evaluating oxidative processes. One of them is thiol/disulfide homeostasis

(ㄷ) This is an Open-Access article distributed under the terms of the Creative Commons Attribution Non-Commercial License (http://creativecommons.org/licenses/by-nc/4.0) which permits unrestricted non-commercial use, distribution, and reproduction in any medium, provided the original work is properly cited. 
$(\mathrm{TDH})$ [12]. Thiols contain a sulfhydryl group (-SH) that is composed of hydrogen and sulfur atoms attached to a carbon atom. Thiols can respond to free radicals for protecting tissues and cells from the damage caused by organic compounds containing reactive oxygen products [13]. A problem in this homeostasis results in a variety of disorders, as the ratio of thiol disulfide plays a critical role in antioxidant protection, detoxification, and signal transduction, regulation of enzymatic activity, apoptosis and cellular signaling mechanisms [14,15].

As a result, thiol/disulfide balance may provide information about the oxidative processes in the human body. The direction of the distortion in this balance may be a sign of oxidative status [16]. Examining dynamic $\mathrm{TDH}$ can provide significant insight into diverse biochemical processes, either normal or abnormal [17]. In this regard, the abnormal state of TDH may affect the pathogenesis of several clinical conditions, such as schizophrenia, neurodegenerative disorders, and bipolar disorder [18-22].

In the light of the findings from previous studies investigating TDH in mental disorders, we investigated whether TDH might be helpful in explaining underlying biological differences such as oxidative processes in UD and bipolar depression (BD).

\section{METHODS}

In this study, the participants were 61 patients diagnosed with BD ( $\mathrm{n}=37)$ and UD $(\mathrm{n}=24)$ according to Diagnostic and Statistical Manual of Mental Disorders, fifth edition, and 50 healthy controls (HC) with no psychiatric and neurologic disorder. Patients with bipolar disorder depressive episode (BD) and unipolar depressive disorder (UD) were diagnosed by two experienced psychiatrists. The participants were evaluated using the Turkish versions of the Hamilton Depression Rating Scale [23-25] and the Young Mania Rating Scale [26,27]. The age range for the inclusion of the participants was 18-65 years old.

Effect size from our previous study [18] between patient and control was 0.56 for disulfide/native thiol ratio. A power analysis revealed that in order for $d=0.56$ effect size of disulfide/native thio to be detected ( $80 \%$ power) as significant at the $5 \%$ level, a sample of 50 participants would be required for patient and control group com- parison. The exclusion criteria were: having an anti-inflammatory treatment, pregnancy, mental retardation, alcohol or drug dependence, neurological illness, any systematic or metabolic disease that may influence oxidative marker concentrations.

The Ethics Committee of Ankara Numune Training and Research Hospital approved the study (Date: 2018, Number: E-18-2244). A written consent from all participants was obtained before the study.

\section{Biochemical Tests}

Blood samples were collected in plain tubes after an overnight fasting. Venous blood ( $5 \mathrm{ml}$ ) was collected from each participant. Serum samples were separated after centrifugation at $1,300 \mathrm{~g}$ for 10 minutes and stored at $-80^{\circ} \mathrm{C}$ until $\mathrm{TDH}$ tests were performed. The automatic and spectrophotometric method developed by Erel and Neselioglu [12] were used to measure thiol/disulfide homeostasis. The mechanism of the method works as such; dynamic and reducible disulfide bonds in the samples were reduced to free functional thiol groups by using sodium borohydride (NaHB4). $\mathrm{NaBH} 4$ was removed with formaldehyde to prevent the reduction of unused reduced sodium borohydride to dithionite-2 nitrobenzoic (DTNB). Levels of Native thiol (SH), total thiol (ToSH), disulfide (SS) were measured. Native thiol and total thiol levels were determined after reaction with DTNB and their levels were measured ultimately. Disulfide bonds in the sample were calculated using the following equation: (total thiolnative thiol) $/ 2$. $\% \mathrm{CV}$ values are $4 \%, 5 \%$, and $13 \%$ for concentrations of $29.1,16.0$, and $7.15 \mu \mathrm{mol} / \mathrm{L}$, respectively. Detection limit of measurement was $2.8-4,000 \mu \mathrm{mol} / \mathrm{L}$.

\section{Statistical Analysis}

In this study, we tested the normal distribution condition using the Shapiro-Wilk test. Normally distributed data were reported as means with standard deviation, and compared with the two-sample $t$ test and one-way analysis of variance. Non-normally distributed data were reported as medians with minimum and maximum values, and compared using the Mann - Whitney $U$ and Kruskal Wallis tests. In the case of pairwise comparison, the significance levels were adjusted using the Bonferroni method. Pearson's chi-squared test and Fisher-FreemanHalton tests were used to compare categorical variables. Correlations between variables were tested using the 
Pearson and Spearman correlation tests. The significance level was set at $p<0.05$. Statistical analyses were performed with IBM SPSS ver. 23.0 (IBM Corp. Released 2015. IBM SPSS Statistics for Windows, Version 23.0; IBM Corp., Armonk, NY, USA).

\section{RESULTS}

In this study, there were no significant differences in terms of age and sex between all three groups. The so- cio-demographic characteristics of the sample are reported in Table 1. Of the BD group, $70 \%$ were on valproic $\mathrm{acid} /$ sodium valproate, $14 \%$ were on lithium, $5 \%$ were on carbamazepine, and $11 \%$ were not on any mood stabilizer treatment. While $78 \%$ of the BD group were on second generation and $3 \%$ were on first generation antipsychotic treatment, $19 \%$ of them were not prescribed with any antipsychotic treatment. Of the BD group, 19\% were using antidepressant treatment. Of the UD group, $29 \%$ were on sertraline, $12.5 \%$ were on escitalopram,

Table 1. Evaluation of socio-demographic characteristics

\begin{tabular}{|c|c|c|c|c|}
\hline Variable & Bipolar depression $(n=37)$ & Unipolar depression $(n=24)$ & Control $(n=50)$ & $p$ value \\
\hline Sex, female/male & $23(62.2) / 14(37.8)$ & $15(62.5) / 9(37.5)$ & $30(60) / 20(40)$ & $0.970^{\mathrm{a}}$ \\
\hline Age $(y r)$ & $38.4 \pm 10.7$ & $40.6 \pm 14.1$ & $37.2 \pm 9.8$ & $0.485^{b}$ \\
\hline Marital status & & & & $0.703^{c}$ \\
\hline Single & $16(43.2)$ & $10(41.7)$ & $0(0)$ & \\
\hline Married & $21(56.8)$ & $13(54.2)$ & $50(100)$ & \\
\hline Divorced & $0(0)$ & $1(4.2)$ & $0(0)$ & \\
\hline Age at disease onset (yr) & $27.5 \pm 10.2$ & $36.1 \pm 12.8$ & - & $0.005^{\mathrm{e}}$ \\
\hline Smoking (packet-yr) & $0(0-30)$ & $0(0-25)$ & - & $0.315^{\mathrm{d}}$ \\
\hline Duration of disease (yr) & $8(3-25)$ & $2(1-15)$ & - & $<0.001^{\mathrm{d}}$ \\
\hline Number of hospitalizations & $2(0-8)$ & $0(0-2)$ & - & $<0.001^{\mathrm{d}}$ \\
\hline Number of previous manic episodes & $2(0-6)$ & - & - & - \\
\hline Number of depressive episodes & $1(0-4)$ & $2(1-4)$ & - & $0.094^{d}$ \\
\hline Young mania rating scale score & $3.2 \pm 1.2$ & - & - & - \\
\hline Hamilton depression scale score & $28.8 \pm 7.3$ & $28.7 \pm 4.9$ & - & $0.722^{\mathrm{c}}$ \\
\hline
\end{tabular}

Descriptive statistics were presented as number $(\%)$, mean \pm standard deviation or median (minimum -maximum) for continuous variables.

${ }^{a}$ Pearson chi-square test. ${ }^{\mathrm{b}}$ One-way ANOVA (analysis of variance). ${ }^{\mathrm{c}}$ Fisher-Freeman-Halton test. ${ }^{\mathrm{d}}$ Mann - Whitney $U$ test. Independent samples $t$ test. The significance level was set at $p<0.05$.

Table 2. Levels of native thiol, total thiol, disulfide, disulfide/native thiol, disulfide/total thiol, and native/total thiol according to groups

\begin{tabular}{|c|c|c|c|c|c|}
\hline Variable & Bipolar depression & Unipolar depression & Control & $p$ value & Pairwise comparison \\
\hline Native thiol (SH) & $310.6 \pm 51.6$ & $327.3 \pm 53.3$ & $344.4 \pm 49.5$ & $0.011^{\mathrm{a}}$ & $\begin{array}{l}\text { BD vs. UD, } p=0.518 \\
\text { BD vs. C, } p=0.009 \\
\text { UD vs. C, } p=0.447\end{array}$ \\
\hline Total thiol (ToSH) & $358.0 \pm 53.5$ & $377.9 \pm 54.7$ & $383.8 \pm 52.1$ & $0.081^{\mathrm{a}}$ & - \\
\hline Disulfide (SS) & $22.15(12.35-49.3)$ & $25.95(17.65-33)$ & $19.23(12.55-31.35)$ & $<0.001^{\mathrm{b}}$ & $\begin{array}{l}\text { BD vs. } U D, p=0.132 \\
\text { BD vs. } C, p=0.015 \\
\text { UD vs. C, } p<0.001\end{array}$ \\
\hline $\begin{array}{l}\text { Disulfide/native thiol } \\
\text { (SS/SH) }\end{array}$ & $6.64(4.38-28.97)$ & $7.91(5.3-12.32)$ & $5.72(3.71-8.26)$ & $<0.001^{b}$ & $\begin{array}{l}\text { BD vs. UD, } p=0.494 \\
\text { BD vs. C, } p=0.001 \\
\text { UD vs. C, } p<0.001\end{array}$ \\
\hline $\begin{array}{l}\text { Disulfide/total thiol } \\
\text { (SS/ToSH) }\end{array}$ & $5.86(4.03-18.34)$ & $6.83(4.8-9.89)$ & $5.13(3.46-7.09)$ & $<0.001^{\mathrm{b}}$ & $\begin{array}{l}\text { BD vs. UD, } p=0.491 \\
\text { BD vs. C, } p=0.001 \\
\text { UD vs. C, } p<0.001\end{array}$ \\
\hline $\begin{array}{l}\text { Native thiol/total thiol } \\
(\mathrm{SH} / \mathrm{ToSH})\end{array}$ & $88.28(63.32-91.94)$ & $86.35(80.23-90.41)$ & $89.74(85.83-93.09)$ & $<0.001^{\mathrm{b}}$ & $\begin{array}{l}\text { BD vs. UD, } p=0.489 \\
\text { BD vs. C, } p<0.001 \\
\text { UD vs. C, } p=0.001\end{array}$ \\
\hline
\end{tabular}

Descriptive statistics were presented as mean \pm standard deviation or median (minimum-maximum) for continuous variables.

$\mathrm{BD}$, bipolar depression; UD, unipolar depression; C, control.

${ }^{a}$ ANOVA (analysis of variance). ${ }^{b}$ Kruskal - Wallis test. Bonferroni correction was used for pairwise comparisons. The significance level was set at $p<$ 0.05 . 
$33.3 \%$ were on fluoxetine, $17 \%$ were on venlafaxine, and $8.2 \%$ were on duloxetine.

There were differences in SS, SS/SH, SS/ToSH between the $\mathrm{BD}$ and the control group, and between the UD and the control group. SS, SS/SH, SS/ToSH were higher in patients with $\mathrm{BD}$ and in patients with UD than in the control group (Table 2).

The HAM-D scores were positively correlated with SS concentrations $(r=0.341, p=0.007), \mathrm{SS} / \mathrm{SH}$ ratio $(r=$ $0.505, p<0.001)$, and SS/ToSH ratio $(r=0.513, p<$ $0.001)$ in BD group. There was no statistically significant correlation between TDH parameters and the HAM-D scores in UD group (data not shown). In both groups, there was no statistically significant correlation of TDH parameters with duration of illness or number of past episodes (data not shown).

\section{DISCUSSION}

$\mathrm{TDH}$ as an antioxidant parameter has been previously investigated in a variety of clinical conditions, such as schizophrenia, bipolar disorder in manic episode and remission, major depressive disorder, general anxiety disorder $[18,21,22,28,29]$. To the best of our knowledge, this is the first study investigating dynamic $\mathrm{TDH}$ in bipolar disorder patients with depressive episodes.

Our findings showing higher SS, SS/SH, SS/ToSH in both $\mathrm{BD}$ and UD than in controls are in line with the previous meta-analysis that has reported decreased antioxidants and antioxidant enzymes in unipolar depression, and increased oxidative stress in both UD and BD $[6,30,31]$. However, we found no evidence for TDH differences between BD and UD.

In patients with UD and BD, depressive episodes often relapse. In a recent study, $\mathrm{SH}$ and $\mathrm{ToSH}$ levels were lower in first episode major depressive patients than in healthy controls [32]. There are also studies reporting that levels of lipid peroxidation products such as malondialdehyde (MDA), are higher in patients with recurrent depression compared to patients with single episode [33]. In the light of these findings, it can be speculated that oxidative damage may be observed even in the first episode and may indicate that the oxidative damage could increase in recurring episodes. In our study, however, we did not observe an association of TDH with the duration of illness or the number of past depressive episodes.
In a study conducted in untreated female patients with major depressive disorder; serum SS level was lower in patients compared with controls, while serum $\mathrm{SH}$ level was higher in the patient group than in the control group [29]. This was considered to be the result of an anti-oxidative compensation mechanism [29].

Our findings revealed positive correlations between oxidative stress markers ( $\mathrm{SS}, \mathrm{SS} / \mathrm{SH}, \mathrm{SS} / \mathrm{ToSH}$ ) and the $\mathrm{HAM}-\mathrm{D}$ scores in BD. A recent study showed that $\mathrm{SH}$ and ToSH levels were negatively correlated with PANSS scores in untreated patients with schizophrenia [21]. In a previous study conducted in female patients with untreated major depressive disorder, a negative correlation was found between plasma SS/ToSH ratio and HAM-D score, which was explained with the anti-oxidative compensation mechanism [29]. Our study indicates that the increase in SS, SS/SH, SS/ToSH levels may be related to disease severity. Future studies are needed to understand whether these markers serve as determinants of disease severity over the course of illness progression.

Antipsychotics, mood stabilizers, and antidepressants can also affect the oxidation process. A recent study examining the level of thiol-disulfide in patients with schizophrenia patients shows that the oxidative processes are influenced by atypical antipsychotic treatment [34]. Mood stabilizer drugs may reduce the level of lipid peroxidation [35]. In the literature, it was also argued that atypical antipsychotic drugs might affect oxidative status by increasing the antioxidant levels and decreasing the oxidative stress [36-39]. A recent study showed that compared to controls, $\mathrm{SH}$ and $\mathrm{ToSH}$ levels were higher in patients with schizophrenia, who were on atypical antipsychotic drugs [34]. In our study, although the majority of the patients with BD were using antipsychotics, there was a shift toward the oxidative stress in the TDH in these patients.

The other studies showed that MDA levels returned to normal levels after antidepressant treatment in patients with depression $[40,41]$. Despite the use of antidepressants in patients with UD in our study, there was a shift toward the oxidative direction in $\mathrm{TDH}$. The recent meta-analysis shows that following an antidepressant medication, the antioxidant levels increase, while the oxidative damage product levels decrease [42].

Previously, we showed that the native thiol and total thiol levels were lower in patients with mania compared to those in remission and controls; and speculated that 
this might be related to malnutrition during manic episodes [18]. There were not any significant differences between the bipolar mania, remission and control groups in terms of their disulfide level in our previous study. In this study, however, disulfide level is higher in UD and BD groups than the control group and disulfide level in BD group also correlated with HAM-D score. This might be an indicator of oxidative stress in depression.

\section{Limitations}

Although TDH has been previously investigated in depression, this is the first study to investigate TDH homeostasis in bipolar depression. Therefore, our findings from the current exploratory analysis require further confirmation in future studies. There are several limitations that should be considered when interpreting the results. The sample size was relatively small. In particular, the low number of UD and BD participants may be insufficient to detect small effect-size differences in $\mathrm{TDH}$ homeostasis between UD and BD.

We could not evaluate the effects of the drugs on the patients since all patients were on treatment in our study. Also, the patients did not have a homogeneous distribution in terms of the medication categories. Another limitation of our study was the failure to eliminate other potential factors that might influence oxidative stress, such as obesity, life-style, and smoking. However, the high prevalence rates of smoking in the general population in Turkey might have mitigated the confounding effects of this limitation. Further, there was no difference in smoking frequencies (packet per year) between UD and BD patients.

\section{Conclusion}

Our findings suggest that there might be an increase in oxidative stress in patients with bipolar and unipolar depression patients compared with that in healthy controls. We found no difference in thiol/disulfide balance between BD and UD, which may imply that there is a common oxidative damage in both disorders. In the future, longitudinal studies with larger sample sizes with medication-free patients are required to understand the role of $\mathrm{TDH}$ homeostasis in depressive disorders.

\section{- Conflicts of Interest}

No potential conflict of interest relevant to this article was reported.

\section{Author Contributions}

Conceptualization: Gamze Erzin, Rabia Nazik Yüksel, Canan Topçuoğlu. Data acquisition: Rabia Nazik Yüksel. Formal analysis: Güven Özkaya, Gamze Erzin. Biochemical analysis: Canan Topçuoğlu, Özcan Erel, Emine Feyza Yurt. Supervision: Erol Göka, Sinan Gülöksüz. Writingoriginal draft: Gamze Erzin, Sinan Gülöksüz. Writing - review \& editing: Gamze Erzin, Güven Özkaya, Erol Göka, Sinan Gülöksüz.

\section{ORCID}

Gamze Erzin

https://orcid.org/0000-0001-8002-5053

Güven Özkaya $\quad$ https://orcid.org/0000-0003-0297-846X

Canan Topçuoğlu https://orcid.org/0000-0002-2058-9380

Rabia Nazik Yüksel https://orcid.org/0000-0003-1635-9176

Özcan Erel https://orcid.org/0000-0002-2996-3236

Emine Feyza Yurt https://orcid.org/0000-0001-5686-7576

Erol Göka

https://orcid.org/0000-0001-7066-2817

Sinan Gülöksüz https://orcid.org/0000-0002-6626-1874

\section{REFERENCES}

1. Kleinman L, Lowin A, Flood E, Gandhi G, Edgell E, Revicki D. Costs of bipolar disorder. Pharmacoeconomics 2003;21:601622.

2. Papakostas Gl, Petersen T, Mahal Y, Mischoulon D, Nierenberg AA, Fava M. Quality of life assessments in major depressive disorder: a review of the literature. Gen Hosp Psychiatry 2004;26:13-17.

3. Drexhage RC, Weigelt K, van Beveren N, Cohen D, Versnel MA, Nolen WA, et al. Immune and neuroimmune alterations in mood disorders and schizophrenia. Int Rev Neurobiol 2011;101:169-201.

4. Lakhan SE, Vieira K, Hamlat E. Biomarkers in psychiatry: drawbacks and potential for misuse. Int Arch Med 2010;3:1.

5. Vaváková M, Ďuračková Z, Trebatická J. Markers of oxidative stress and neuroprogression in depression disorder. Oxid Med Cell Longev 2015;2015:898393.

6. Andreazza AC, Kauer-Sant'anna M, Frey BN, Bond DJ, Kapczinski F, Young LT, et al. Oxidative stress markers in bipolar disorder: a meta-analysis. J Affect Disord 2008;111: 135-144.

7. Maes M, Galecki P, Chang YS, Berk M. A review on the oxidative and nitrosative stress (O\&NS) pathways in major depression and their possible contribution to the (neuro)degenerative processes in that illness. Prog Neuropsychopharmacol Biol Psychiatry 2011;35:676-692.

8. Siwek M, Sowa-Kućma M, Dudek D, Styczeń K, Szewczyk B, 
Kotarska K, et al. Oxidative stress markers in affective disorders. Pharmacol Rep 2013;65:1558-1571.

9. Halliwell B. Oxidative stress and neurodegeneration: where are we now? J Neurochem 2006;97:1634-1658.

10. Halliwell B. Free radicals and antioxidants - quo vadis? Trends Pharmacol Sci 2011;32:125-130.

11. Halliwell B, Lee CY. Using isoprostanes as biomarkers of oxidative stress: some rarely considered issues. Antioxid Redox Signal 2010;13:145-156.

12. Erel O, Neselioglu S. A novel and automated assay for thiol/disulphide homeostasis. Clin Biochem 2014;47:326-332.

13. Kemp M, Go YM, Jones DP. Nonequilibrium thermodynamics of thiol/disulfide redox systems: a perspective on redox systems biology. Free Radic Biol Med 2008;44:921-937.

14. Circu ML, Aw TY. Reactive oxygen species, cellular redox systems, and apoptosis. Free Radic Biol Med 2010;48:749-762.

15. Ozyazici S, Karateke F, Turan U, Kuvvetli A, Kilavuz H, Karakaya B, et al. A novel oxidative stress mediator in acute appendicitis: thiol/disulphide homeostasis. Mediators Inflamm 2016;2016:6761050.

16. Biswas S, Chida AS, Rahman I. Redox modifications of protein-thiols: emerging roles in cell signaling. Biochem Pharmacol 2006; 71:551-564.

17. Incecik F, Avcıoğlu G, Erel Ö, Neşelioğlu S, Hergüner OM. Dynamic thiol/disulphide homeostasis in children with Duchenne muscular dystrophy. Acta Neurol Belg 2019;119: 215-218.

18. Erzin G, Kotan VO, Topçuoğlu C, Özkaya G, Erel Ö, Yüksel $\mathrm{RN}$, et al. Thiol/disulphide homeostasis in bipolar disorder. Psychiatry Res 2018;261:237-242.

19. Smeyne M, Smeyne RJ. Glutathione metabolism and Parkinson's disease. Free Radic Biol Med 2013;62:13-25.

20. Steele ML, Fuller S, Maczurek AE, Kersaitis C, Ooi L, Münch G. Chronic inflammation alters production and release of glutathione and related thiols in human U373 astroglial cells. Cell Mol Neurobiol 2013;33:19-30.

21. Topcuoglu C, Bakirhan A, Yilmaz FM, Neselioglu S, Erel O, Sahiner SY. Thiol/disulfide homeostasis in untreated schizophrenia patients. Psychiatry Res 2017;251:212-216.

22. Ünal K, Erzin G, Yüksel RN, Alisik M, Erel Ö. Thiol/disulphide homeostasis in schizophrenia patients with positive symptoms. Nord J Psychiatry 2018;72:281-284.

23. Akdemir A, Türkçapar MH, Orsel SD, Demirergi N, Dag I, Ozbay MH. Reliability and validity of the Turkish version of the Hamilton Depression Rating Scale. Compr Psychiatry 2001;42:161-165.

24. Hamilton M. A rating scale for depression. J Neurol Neurosurg Psychiatry 1960;23:56-62.

25. Williams JB. A structured interview guide for the Hamilton Depression Rating Scale. Arch Gen Psychiatry 1988;45:742747.

26. Young RC, Biggs JT, Ziegler VE, Meyer DA. A rating scale for mania: reliability, validity and sensitivity. $B r$ J Psychiatry
1978; 133:429-435.

27. Karadağ F, Oral T, Yalçin FA, Erten E. [Reliability and validity of Turkish translation of Young Mania Rating Scale]. Turk Psikiyatri Derg 2002;13:107-114. Turkish.

28. Asoğlu M, Kılıçaslan F, Beginoğlu Ö, Fedai Ü, Akıl Ö, Çelik $\mathrm{H}$, et al. Thiol/disulphide homeostasis as a new oxidative stress marker in untreated patients with generalized anxiety disorder. Anadolu Psikiyatri Derg 2018;19:143-149.

29. Baykan H, Durmaz O, Baykan Ö, Alışık M, Şahin MC, Karlıdere T, et al. Dynamic thiol/disulphide homeostasis as a novel oxidative stress marker in women with major depressive disorder. Anadolu Psikiyatri Derg 2018;19:135-142.

30. Palta P, Samuel LJ, Miller ER 3rd, Szanton SL. Depression and oxidative stress: results from a meta-analysis of observational studies. Psychosom Med 2014;76:12-19.

31. Black CN, Bot M, Scheffer PG, Cuijpers P, Penninx BW. Is depression associated with increased oxidative stress? A systematic review and meta-analysis. Psychoneuroendocrinology 2015;51:164-175.

32. Karaaslan Ö, Hacımusalar Y, Bal C, Ercan M. Evaluation of thiol/disulfide homeostasis in patients with a first episode of major depressive disorder. Med Sci Discov 2019;6:1-7.

33. Stefanescu C, Ciobica A. The relevance of oxidative stress status in first episode and recurrent depression. J Affect Disord 2012;143:34-38.

34. Dogan HO, Ersan EE, Aydin H, Erdoğan S, Erşan S, Alişik M, et al. Thiol disulfide homeostasis in schizophrenic patients using atypical antipsychotic drugs. Clin Psychopharmacol Neurosci 2018;16:39-45.

35. Shao L, Young LT, Wang JF. Chronic treatment with mood stabilizers lithium and valproate prevents excitotoxicity by inhibiting oxidative stress in rat cerebral cortical cells. Biol Psychiatry 2005;58:879-884.

36. Al-Chalabi BM, Thanoon IA, Ahmed FA. Potential effect of olanzapine on total antioxidant status and lipid peroxidation in schizophrenic patients. Neuropsychobiology 2009;59:8-11.

37. Evans DR, Parikh VV, Khan MM, Coussons C, Buckley PF, Mahadik SP. Red blood cell membrane essential fatty acid metabolism in early psychotic patients following antipsychotic drug treatment. Prostaglandins Leukot Essent Fatty Acids 2003;69:393-399.

38. Park SW, Phuong VT, Lee CH, Lee JG, Seo MK, Cho HY, et al. Effects of antipsychotic drugs on BDNF, GSK-3 $\beta$, and $\beta$-catenin expression in rats subjected to immobilization stress. Neurosci Res 2011;71:335-340.

39. Wei Z, Bai O, Richardson JS, Mousseau DD, Li XM. Olanzapine protects PC12 cells from oxidative stress induced by hydrogen peroxide. J Neurosci Res 2003;73:364-368.

40. Bilici M, Efe H, Köroğlu MA, Uydu HA, Bekaroğlu M, Değer O. Antioxidative enzyme activities and lipid peroxidation in major depression: alterations by antidepressant treatments. J Affect Disord 2001;64:43-51.

41. Kotan VO, Sarandol E, Kirhan E, Ozkaya G, Kirli S. Effects of 
long-term antidepressant treatment on oxidative status in major depressive disorder: a 24-week follow-up study. Prog Neuropsychopharmacol Biol Psychiatry 2011;35:1284-1290.
42. Liu T, Zhong S, Liao X, Chen J, He T, Lai S, et al. A meta-analysis of oxidative stress markers in depression. PLoS One 2015; 10:e0138904. 